\title{
Effects of Cooling Rate on the Microstructure, Mechanical Properties and Corrosion Resistance of $6 x \times x$ Aluminium Alloy
}

\author{
Joseph B. Agboola, Emmanuel S. Anyoku, Atinuke M. Oladoye
}

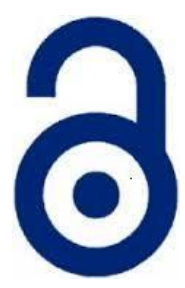

Received: 14 September 2020

Accepted: 07 January 2021

Published: 30 January 2021

Publisher: Deer Hill Publications

(c) 2021 The Author(s)

Creative Commons: CC BY 4.0

\begin{abstract}
The applicability of materials is highly dependent on its microstructure and mechanical properties. Aluminium alloy is being used extensively under diverse conditions. This study investigates the effects of cooling rate on the microstructure, mechanical properties and corrosion resistance of $6 \times x \times$-series aluminium alloy. Aluminium ingot was melted in a muffle furnace and cast into rods. The cooling rate was controlled by holding the moulds at different temperatures. Microstructural characteristics were examined by optical microscopy. Mechanical properties such as impact strength, hardness, and tensile strength were analysed using standard methods. Corrosion resistance was evaluated by potentiodynamic polarization. It was found that microstructures are dominated by ferrite and pearlite phases with different morphologies and grain sizes depending on the cooling rate. Increasing the cooling rate resulted in microstructural refinement and chemical homogeneity, improvement in mechanical properties and corrosion resistance of the $6 \times x x$ alloy.
\end{abstract}

Keywords: 6xxx Al, Cooling rate, mechanical properties, corrosion resistance, $\mathrm{HCl}$

\section{INTRODUCTION.}

Most applications of aluminium alloy are dependent on their mechanical properties which are mainly dependent on microstructure [1]. 6xxx-series aluminium alloy is widely used as structural materials in aircraft and automobile because of its high strength and low density [2]. However, it has been observed that $6 x x x$ aluminium alloy despite its good mechanical properties do undergo some form of corrosion attack, the effects of which results to loss of human lives and other economic consequences [3]. Corrosion process in aluminium alloy has been attributed to heterogeneous microstructure containing intermetallic phases and precipitates that are usually present at the grain boundaries [4]. The effects of cooling rate on mechanical behaviour of bulk cast of A380 aluminium alloy by using copper as a die material for attaining fast heat transfer during solidification has been investigated. Their results showed that a faster cooling rate improved the ultimate tensile strength [5]. However, their work did not investigate the effects of cooling rate on corrosion behaviour of the alloy. It has been established that mechanical properties of aluminium alloy increased as the solidification time reduces [6]. It has also been established that castings at faster cooling rate yields high value of yield strength, ultimate tensile strength, ductility, hardness and resistance to impact in the cast [7]. The influence of cooling rate on solidification behaviour of AA2618 aluminium alloy has been examined [8], [9] and [10]. They all concluded that under slow cooling conditions, the alloy was of complex microstructures with lots of eutectic compounds and that increasing cooling rate suppressed the formation of intermetallic $\mathrm{Al}_{9} \mathrm{FeNi}$.

Despite several efforts that have been made for refining microstructure of aluminium alloy casting to improve mechanical properties suitable for application in automobile industry, research effort on the effect of cooling rate on microstructure and corrosion behaviour of $6 x x x$ alloy is rare. Hence, this study investigates the effect of cooling rate during casting process on microstructure, mechanical properties and corrosion behaviour of $6 \times x x$-series aluminium alloy.

Agboola, J.B. 凶, Emmanuel, S.A. and Oladoye, A.M.

Department of Metallurgical and Materials Engineering

Faculty of Engineering, University of Lagos, Akoka, Nigeria

E-mail: joeagboola@unilag.edu.ng

Reference: Agboola, J.B., Emmanuel, S.A. and Oladoye, A.M. (2021). Effects of Cooling Rate on the Microstructure, Mechanical Properties and Corrosion Resistance of 6xxx Aluminium Alloy. International Journal of Engineering Materials and Manufacture, 6(1), 43-49. 


\section{MATERIALS, EQUIPMENT AND SAMPLES PREPARATION}

\subsection{Materials and Equipment}

The materials used in the study were 6xxx-series aluminium alloy, obtained from Nigalex, Nigeria while the equipment employed in the work were Universal Testing Machine (UTM) model FS 50AT, Muffle Furnace, Die moulds, Pyrometer, Brinell Hardness tester, Charpy impact tester and Gamry 1000T Potentiostat/Galvnostat.

\subsection{Melting and Casting}

$6 x x x$ aluminium alloy is melted using muffle furnace. Prior to pouring, the moulds were treated to four different temperature conditions in order to control the cooling rate. Table 1 shows specimens' identification according to mould condition. A pyrometer was placed close to the moulds cavity to measure the temperature. The temperature data acquired during cooling was used to plot cooling curve. Cooling rate curves were obtained by taking the slope at each temperature of time versus temperature curves.

\subsection{Samples Preparation}

Samples were prepared from the cast $6 \times x x$-series aluminium alloy. The chemical compositions of the alloy used is shown in Tables 2. The tensile test samples were prepared based on ASTM E8M 16 [23], with gauge length of 45 $\mathrm{mm}$ and radius of $9 \mathrm{~mm}$. The hardness test samples were prepared by cutting a sample of the cast Aluminium. The sectioned samples were thereafter ground sequentially with $\mathrm{SiC}$ paper of different grit paper up to 1200 in accordance with ASTM E384. The impact samples were machined to $10 \mathrm{~mm}$ by $10 \mathrm{~mm}$ cross section with a $V$ notch tip radius of $0.5 \mathrm{~mm}$ with notch angles of $45^{\circ}$.

\subsection{Tensile Test}

The test was carried out on universal testing machine (UTM) model FS- 50AT with maximum load capacity of 50 $\mathrm{kN}$. The strain rate was $10^{-3} / \mathrm{s}$. Tensile force was applied until the sample reached its failure point. The stress - strain relationship parameters for each of the sample were obtained and recorded.

\subsection{Impact Test}

Impact test was performed on test specimen machined to a $10 \mathrm{~mm}$ by $10 \mathrm{~mm}$ cross section with a $V$ notch using a universal impact testing machine model IT30 with maximum capacity of $360 \mathrm{~J} \pm 1(\mathrm{~J})$. The arm of the machine was allowed to swing freely to ensure freedom of movement of the striker. Each sample was clamped to the anvil and rigidly tightened by lever at the base of the machine. The pointer was set to zero-energy position and the striker released from a fixed height throughout the procedure. The average of the three energy values absorbed by each sample as indicated by the loose registering pointer on scale were record.

\subsection{Hardness Test}

The surfaces of the samples were subjected to a compressive load of $0.3 \mathrm{kgf}$ for $15 \mathrm{~s}$ using Shimadzu HMV-2000 Micro Hardness Tester. Diamond shaped indenter with square-based pyramid inclined at an angle of $136^{\circ}$ between opposite faces was used. Three indentation measurements were taken on each sample in different locations and the average was used to evaluate the hardness of the materials. The Vickers hardness value $\left(\mathrm{HV}_{0.2}\right)$ was calculated according to (Meyers and Chawla, 1999) from equation 3.1.

$$
H V_{0.2}=\frac{F}{A} \approx \frac{1.8544 F}{d^{2}}
$$

Where $\mathrm{F}$ is the applied load in Kgf, $\mathrm{A}$ is the surface area of the resulting indentation in square millimetre and $\mathrm{d}$ is the length of the diagonal of the resulting indentation in millimetre.

Table I: Identification of Cast Specimens

\begin{tabular}{cl}
\hline Specimen & Cooling Method \\
\hline A & alloy cooled in mould at room temperature \\
B & alloy cooled in mould immersed in ice-block \\
C & alloy cooled at mould temperature of $140^{\circ} \mathrm{C}$ \\
D & alloy cooled at mould temperature of $230^{\circ} \mathrm{C}$ \\
\hline
\end{tabular}

Table 2: Chemical composition of $6 x x x$ aluminium alloy

\begin{tabular}{cccccccccc}
\hline Composition & $\mathrm{Mg}$ & $\mathrm{Si}$ & $\mathrm{Cu}$ & $\mathrm{Cr}$ & $\mathrm{Fe}$ & $\mathrm{Mn}$ & $\mathrm{Zn}$ & $\mathrm{Ti}$ & $\mathrm{Al}$ \\
\hline $\mathrm{Wt}_{\mathrm{t}} \%$ & 0.834 & 0.594 & 0.194 & 0.051 & 0.182 & 0.028 & 0.023 & 0.016 & 98.078 \\
\hline
\end{tabular}




\subsection{Microstructure}

Specimens for microstructural analysis were prepared by grinding with silicon carbide emery paper and thereafter polishing the samples with Grinding and Polishing Machine QPOL $250 \mathrm{M} 2$ followed by etching with diluted hydrofluoric acid while the microstructural analysis was performed using optical microscope Olympus model $G \times 71$, at 200 magnifications.

\subsection{Corrosion Test}

Corrosion resistance of the as-cast samples was evaluated using a conventional three electrode system consisting of the different aluminium samples as the working electrodes, a graphite rod as the counter electrode and a saturated calomel electrode (SCE) as the reference electrode. The working electrode was embedded in the epoxy with an exposed area of $100 \mathrm{~mm}^{2}$. Pontentiodynamic polarisation experiments were conducted using a Gamry interface 1000T potentiostat (Gamry Instruments, USA). The electrolyte used for the test was $1 \mathrm{M}$ hydrochloric acid prepared from concentrated $\mathrm{HCl}$ (37 wt.\% analytical grade). Pontentiodynamic polarisation was conducted at scan rate of $1 \mathrm{mV} / \mathrm{s}$ from $-250 \mathrm{mV}$ vs OCP (Open circuit potential) to about $-400 \mathrm{mV}$. Prior to this test, OCP was conducted for 10 minutes, Experiments was repeated minimum two times.

\section{RESULTS AND DISCUSSION}

\subsection{Cooling Rate Evaluation}

The $6 \times x x$-series aluminium alloy was cooled under four different cooling conditions, and the cooling rate was measured using a thermocouple. A plot of temperature versus time for different cooling modes was plotted as shown in Figure 1 and the cooling rate was calculated from the obtained cooling curves.

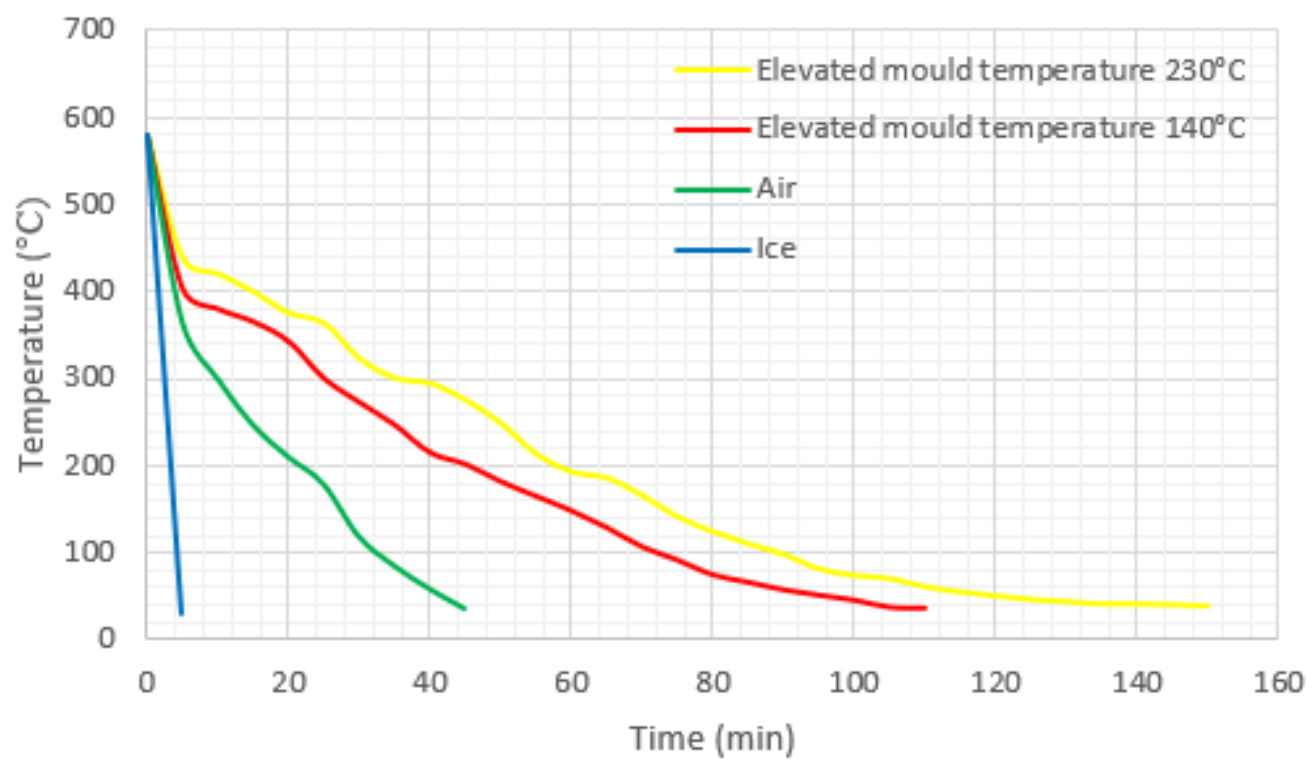

Figure 1: Cooling curves of $6 x x x$-series aluminium alloy under different mould temperature.

Figure 2 a-d shows the graphs of cooling rate versus temperature for $6 x x x$ aluminium alloy cooled under different cooling conditions. From figure $2 \mathrm{a}-\mathrm{d}$, it is found that increasing the temperature led to reduction of cooling rate. Figure $2 \mathrm{a}$ shows the cooling rate curve under slow cooling at room temperature and the average cooling rate was $45^{\circ} \mathrm{C} / \mathrm{s}$. The overall cooling rate tends to be fast and uniform. Figure $2 \mathrm{~b}$ shows the cooling rate curve under slow cooling in ice-cooled mould. The average cooling rate was $50^{\circ} \mathrm{C} / \mathrm{s}$. The overall cooling rate in this cooling mode is faster compared with room temperature condition. The cooling rate curve obtained under $140^{\circ} \mathrm{C}$ cooling condition is shown in Figure $2 \mathrm{c}$. As can be seen from the figure, the cooling rate remained steady at average cooling rate of $35^{\circ} \mathrm{C} / \mathrm{min}$. Figure $2 \mathrm{~d}$ shows cooling rate curve for $230^{\circ} \mathrm{C}$. The trend of cooling rate changed in a similar way to cooling at $140^{\circ} \mathrm{C}$. However, the cooling rate was $28^{\circ} \mathrm{C} / \mathrm{min}$. It can be seen that the $\mathrm{dT} / \mathrm{dt}$ curve, having reached the peak, exhibits a straight line parallel to the horizontal axis.

\subsection{Microstructure at Different Cooling Rates}

Figure 3 shows the optical microstructures of $6 x x x$ aluminium alloy solidified at different cooling rates. It can be seen that the faster the cooling rate, the smaller the grains and the more refined the microstructure. Plate 1 shows the microstructures of $6 \times x \times$ aluminium alloy under different cooling conditions. Plates $1 \mathrm{a}$ and $1 \mathrm{~b}$ shows the microstructures obtained at room temperature and ice cooled conditions respectively. 

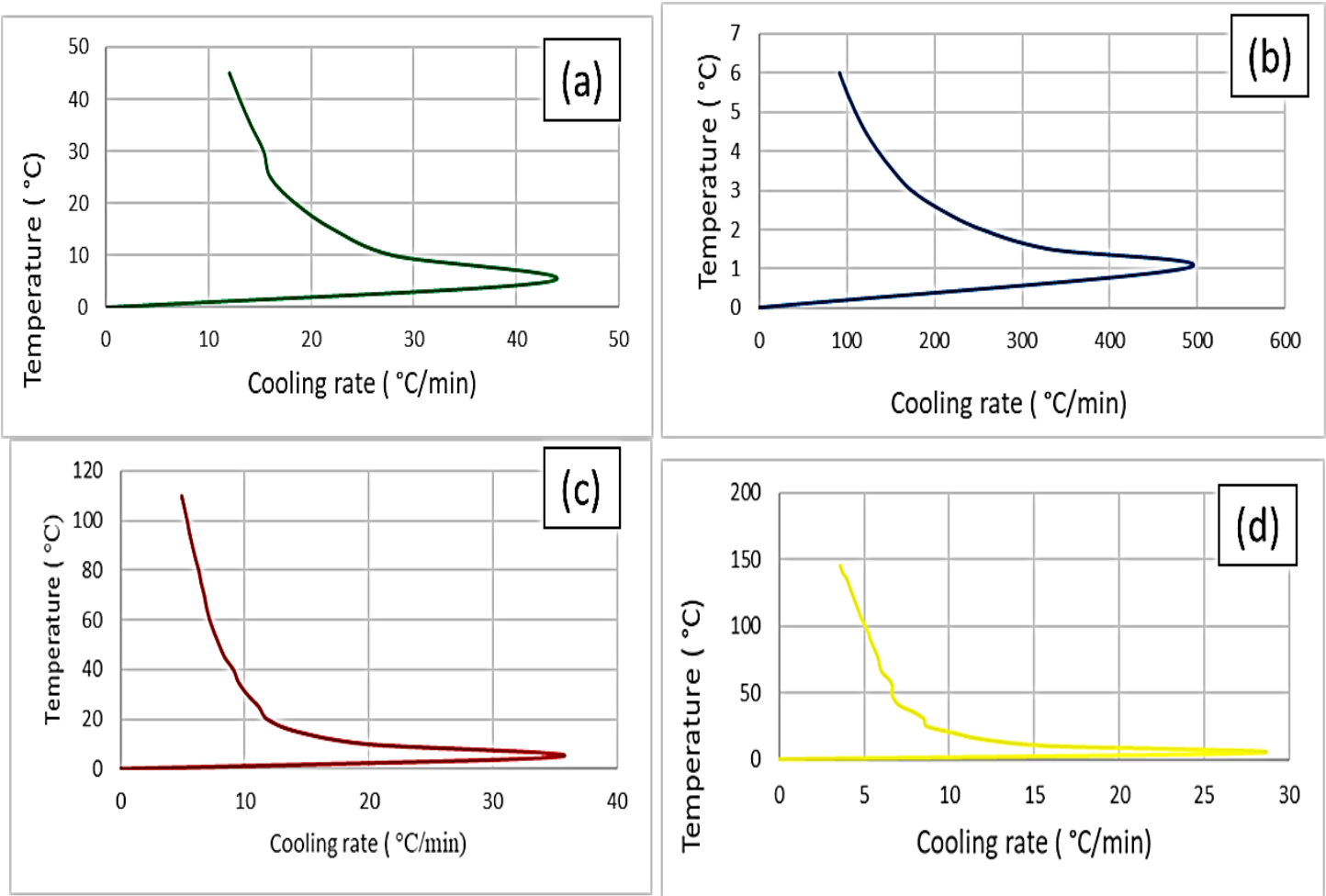

Figure 2: Cooling rate curve of cast specimen (a) cooled in mould at room temperature (b) cooled in mould immersed in ice block (c) cooled in mould at $140{ }^{\circ} \mathrm{C}$ (d) cooled in mould at $230^{\circ} \mathrm{C}$.
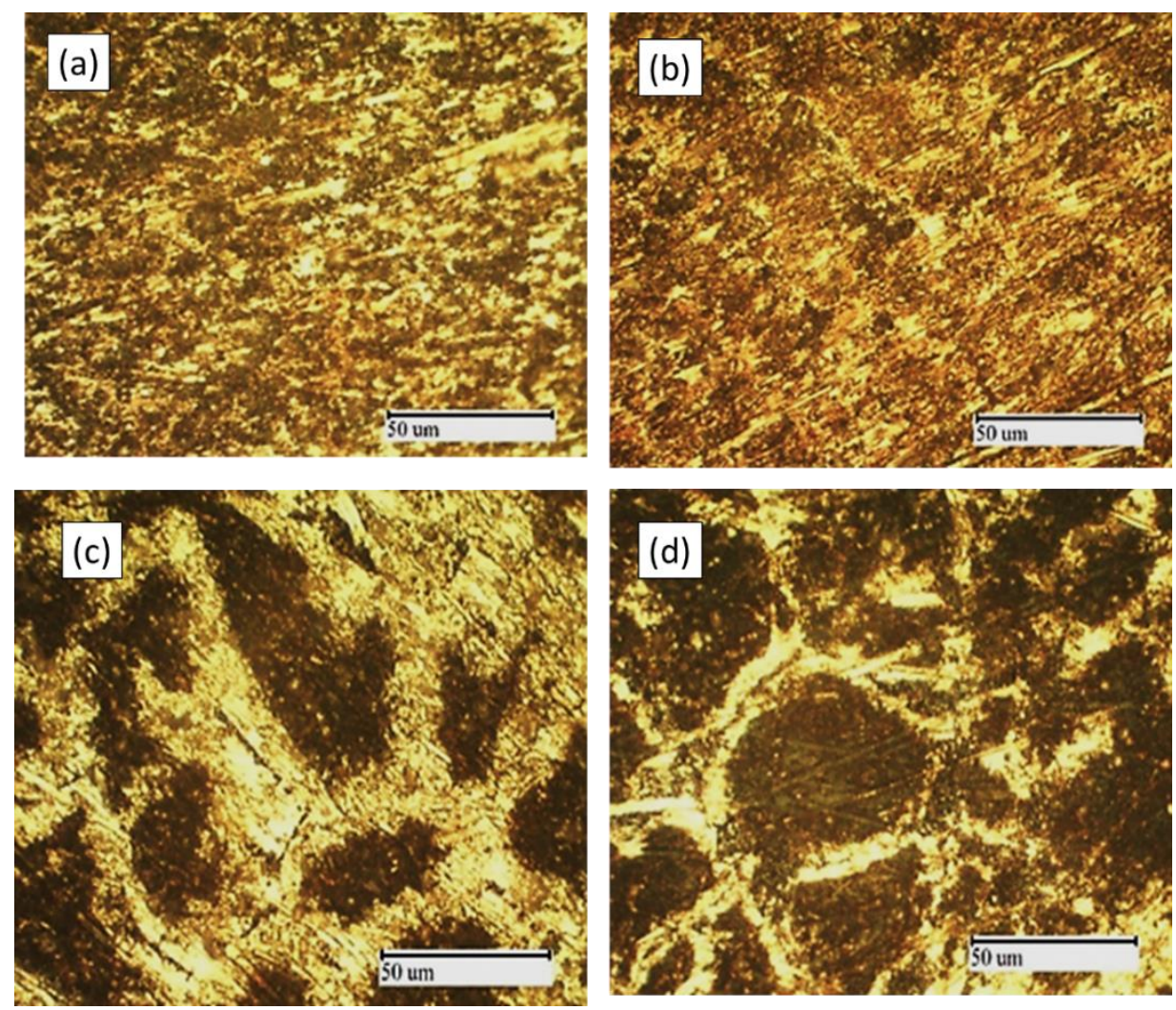

Figure 3: Plate 1: Microstructure of the $6 x \times x$ aluminium alloy under different cooling rates (a) mould was cooled at room temperature (b) mould was cooled in ice block (c) mould was cooled mould temperature $430^{\circ} \mathrm{C}$ (d) mould was cooled at $230^{\circ} \mathrm{C}$. 
The grain size appears smaller finer and evenly dispersed. Plates $1 c$ and $1 \mathrm{~d}$ shows the microstructure obtained at high temperatures. As can be seen in Plates $1 \mathrm{c}$ and $1 \mathrm{~d}$, the grains appear larger in size, because the alloy remains at high temperature for a long time [14]. hence, recrystallization followed by grain growth occurs. A large number of precipitates appear in the crystal. It can be seen from the above description that there are significant differences in the size and morphology of the crystal grains in the as-cast alloy under different cooling condition. With an increase of cooling rate, finer crystal grains were found in the alloy.

\subsection{Mechanical Tests Results}

Figures 4 shows the effects of cooling rate on Ultimate tensile strength (UTS), Hardness and Impact strength of 6xxx aluminium alloy. It is seen from table 3 that tensile strength increases with increasing cooling rate. The hardness measurement indicated that ice-cooled samples had higher hardness compared to air-cooled and samples cooled at elevated temperatures. The UTS increase from 39.6 to $45.3 \mathrm{MPa}$ as the cooling rate increase. The increase in strength is due to the presence of finer ferrite-pearlite structure. The lowest value of UTS recorded in sample cooled at 230 ${ }^{\circ} \mathrm{C}$ is due to the presence of coarser pearlite structure [15]. With faster cooling rate, the transformation temperature is lowered resulting in finer pearlite structure. This in turn increase the strength with increase in cooling rate. The impact energy value decreased from $54 \mathrm{Kj} / \mathrm{m}^{2}-64 \mathrm{Kj} / \mathrm{m}^{2}$ due to increase in cooling rate which led to the formation of finer and harder phases in the microstructure. Whereas ice - cooled samples exhibited least impact energy value of $54 \mathrm{Kj} / \mathrm{m}^{2}$ because of harder micro constituents, samples cooled at $230^{\circ} \mathrm{C}$ reflected the highest impact energy values on account of the softer and coarser pearlite structures. The higher the cooling rate, the higher the strength of the materials due to fine grains. The grains in the ice-cooled and air-cooled samples were finer and more uniform. This observation agrees with Elahetia (2013) that mechanical properties increased with increase in cooling rate.

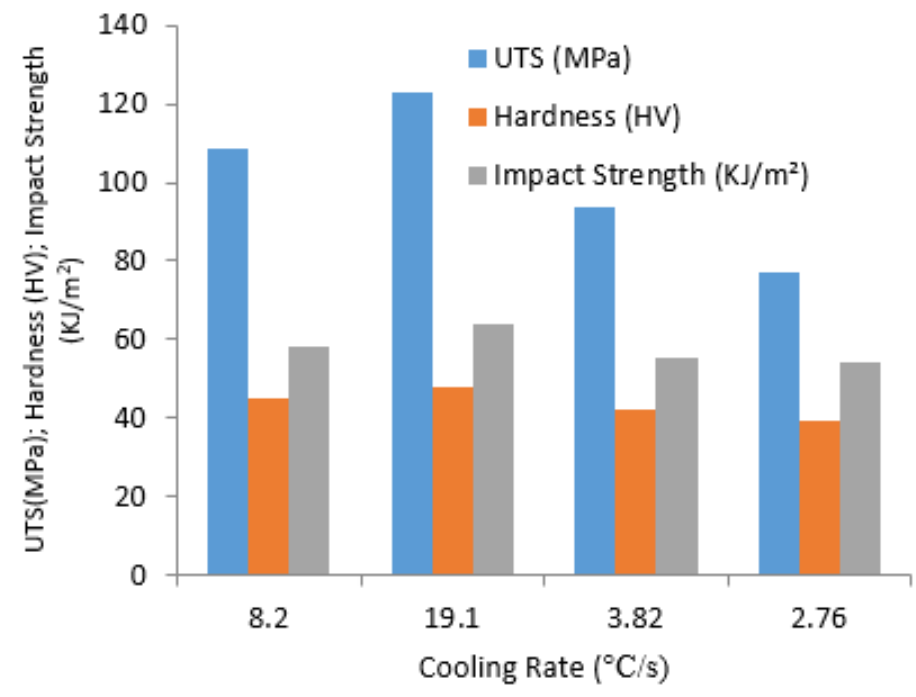

Figure 4: Variation in ultimate tensile strength UTS, Hardness and Impact strength with cooling rate.

Table 3: Effects of cooling rate on the mechanical properties

\begin{tabular}{ccccc}
\hline Specimen & $\begin{array}{c}\text { Cooling rate } \\
\left({ }^{\circ} \mathrm{C} / \mathrm{min}\right)\end{array}$ & $\begin{array}{c}\text { UTS } \\
(\mathrm{MPa})\end{array}$ & $\begin{array}{c}\text { Hardness } \\
(\mathrm{HV} 1)\end{array}$ & $\begin{array}{c}\text { Impact strength } \\
\left(\mathrm{KJ} / \mathrm{m}^{2}\right)\end{array}$ \\
\hline A & 8.2 & 108.5 & 45.3 & 58 \\
B & 19.1 & 122.6 & 48 & 64 \\
C & 3.82 & 93.58 & 42.3 & 55.3 \\
D & 2.76 & 76.95 & 39.6 & 54 \\
\hline
\end{tabular}

\subsection{Electrochemical Results}

Figures 5(a-d) shows the potentiodynamic polarization curves of the as-cast aluminium alloys cooled under various conditions in $1.0 \mathrm{M} \mathrm{HCl}$. The corrosion properties estimated form the curves are presented in Table 2. Generally, a high corrosion potential and a low corrosion current density indicates a higher resistance of the material to dissolution in the given electrolyte. From Table 3, it can be observed that the higher the cooling rate of the casting, the better the corrosion resistance with the samples cooled in ice block exhibiting the best corrosion resistance. This enhancement on corrosion resistance as cooling rate increased can be attributed to grain refinement. 

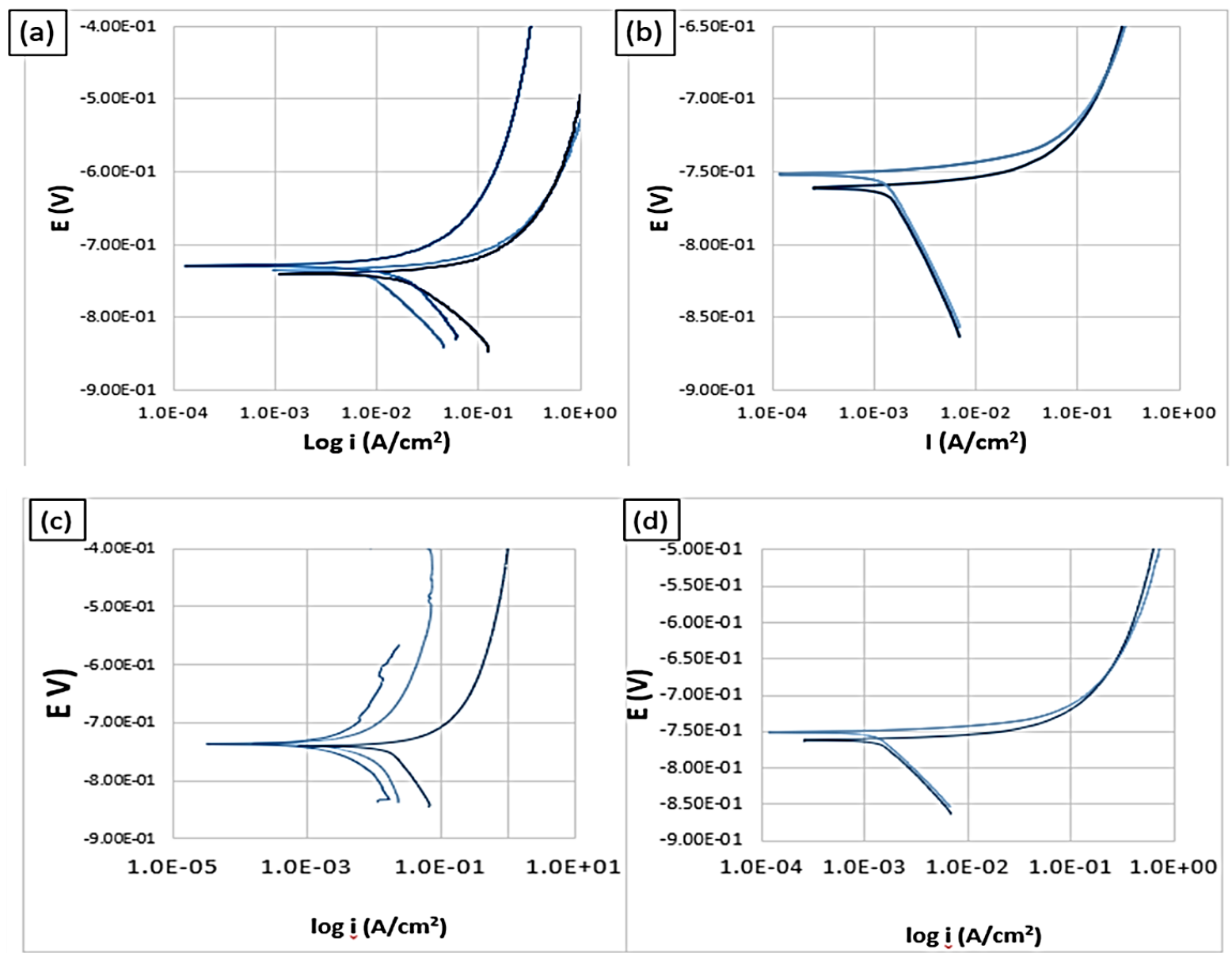

Figure 5: Potentiodynamic curves for $6 x x x$ Aluminium cast samples cooled in (A) air) b) room temperature (b) mould in ice black) c) in mould at $140^{\circ} \mathrm{C}$.(d) cooled in mould at $230^{\circ} \mathrm{C}$.

Table 4: Corrosion data of 6xxx aluminium alloy under different cooling conditions.

\begin{tabular}{clccc}
\hline Specimen & Cooling conditions & $\begin{array}{c}\text { Cooling rate } \\
\left({ }^{\circ} \mathrm{C} / \mathrm{min}\right)\end{array}$ & $\begin{array}{c}\mathrm{I}(\mathrm{corr}) \\
\mathrm{mA} / \mathrm{cm}^{2}\end{array}$ & $\begin{array}{c}\mathrm{E} \text { (corr) } \\
\mathrm{mV}\end{array}$ \\
\hline $\mathrm{A}$ & $\begin{array}{l}\text { Mould maintained at room } \\
\text { temperature }\end{array}$ & 8.2 & 7.83 & -729 \\
$\mathrm{~B}$ & mould immersed in Ice-block & 19.1 & 1.27 & -752 \\
$\mathrm{C}$ & Mould at $140^{\circ} \mathrm{C}$ & 3.82 & 4.11 & -736 \\
$\mathrm{D}$ & Mould at $230^{\circ} \mathrm{C}$ & 2.76 & 8.03 & -750 \\
\hline
\end{tabular}

\section{CONCLUSIONS}

Different cooling rates during casting were investigated in order to investigate the effects of cooling rate on the microstructure, mechanical properties and corrosion behaviour of $6 x x x$-series aluminium alloy. On the basis of the results of the investigation, the following conclusions are drawn:

1. Increasing cooling rate resulted in finer and evenly distributed grains.

2. Rapidly solidified cast has very good strength which is basically due to finer grains and homogenous microstructures.

3. The corrosion resistance and mechanical properties improved with the increasing cooling rate.

4. The improvement in the corrosion resistance is attributed to the microstructural refinement and chemical homogeneity. 


\section{REFERENCES}

1. Akhil, S. \& Sellamuthu, R. (2014). The effect of section size on cooling rate, microstructure and mechanical properties of A356 aluminium alloy casting. Advances in Manufacturing and Materials Engineering; pp. 362368. ScienceDirect.

2. Raja, S. T. (2011). Stress corrosion cracking. Theory and practice, Cambridge, UK: Woodhead Publishing Limited; pp. 608-650.

3. Shimizu, N.K. (2014). High Resolution SEM investigation of Intercrystalline Corrosion on 6000 series aluminium alloy with low copper content. ECS Electrochemistry Letters.

4. Sinyavskii, U. (2004). On the mechanism of Intergranular corrosion of Aluminium Alloys. Protection of Metals, 481-490.

5. Mohandass, A.S. (2014). The effect of cooling rate on mechanical behavior of bulk cast of A380 aluminium alloy. International journal of engineering and technology, 374-380.

6. Liu Y.L., Liu, M.L. Luo L., Wang J.J., Liu C.Z. (2014). The Solidification behavior of AA2618 Aluminium alloy and influence of cooling rate. Materials (Basel) 7(12). 7875-7890.

7. American Society for Testing and Materials, ASTM-G31-72, American Society for Testing and Materials, Philadelphia, PA, 2004.

8. Xia,Y. Zhang,B. Wang,Y. Qian,M. Geng,L. (2012). Mater. Sci. Eng. C 32 (4) 665- 669.

9. Zhang,B., Hou,Y., Wang, X., Wang,Y., Geng,L. (2011) Mater. Sci. Eng. C 31; 1667-1673.

10. Ralston,K.D. Birbilis,N.(2010); Effect of grain size on corrosion: a review, Corrosion 66, 1-13.

11. Ou, M.G.; Zhang, S.; Song, H.C.; Liang, Y.L. (2017) Effects of different cooling methods on microstructure and mechanical properties of TC4 alloy; Proceedings of the Chinese Materials Conference, Yinchuan, China; Springer: Singapore; pp. 539-547.

12. Hichem, F.; Rebai, G. (2015); Study of dispersoid particles in two Al-Mg-Si aluminium alloys and their effects on the recrystallization. Appl. Phys. A,119, 1-5.

13. Zhang, X.K.; Guo, M.X.; Zhang, J.S.; Zhuang, L.Z., (2016); Dissolution of precipitates during solution treatment of Al-Mg-Si-Cu alloys. Metall. Mater. Trans., 47, 608- 617.

14. Elahetia, \& Maube, S. (2013). Effect of short cycle heat treatment and cooling Rate on microstructure and chemical properties of recycled aluminium sand casting; A thesis submitted in partial fulfilment for the degree of Master of Science in Mechanical Engineering in the Jomo- Kenyatta University of Agriculture and Technology.

15. Equbal, M.I., Alam, P., Ohdar, R., Anand, K.A., Alam, M.S., (2016); Effect of Cooling Rate on the Microstructure and Mechanical Properties of Medium Carbon Steel; International Journal of Metallurgical Engineering; 5(2): 21-24 